\title{
Physical Competition Increases Dehydroepiandrosterone (DHEA) and Androstenedione rather than Testosterone among Juvenile Boy Soccer Players
}

\author{
Timothy S. McHale ${ }^{1}$ - David T. Zava ${ }^{2}$. \\ David Hales $^{3} \cdot$ Peter B. Gray ${ }^{1}$
}

Received: 18 December 2014 /Revised: 8 July 2015 / Accepted: 13 July 2015 /

Published online: 21 July 2015

C Springer International Publishing 2015

\begin{abstract}
We examined potential changes in salivary DHEA, androstenedione, cortisol, testosterone, and cortisol/DHEA ratio in boys in response to soccer practice and soccer match competition. To our knowledge, this study is the first to explore the impacts of athletic competition on salivary steroid hormone change in juvenile boy soccer players. Boys from five different Las Vegas, Nevada teams provided saliva samples during soccer practice $(N=28)$, with four out of five teams providing saliva samples during a soccer match $(N=26)$. All participants were aged $8-10$ years. A Wilcoxon Signed-Rank Sum Test and standard linear regression analyses were performed to assess the change in hormone concentrations during soccer practice and soccer match competition. Results revealed a statistically significant rise in boys' DHEA concentrations during both practice and match play. Androstenedione significantly increased during the match competition only. Cortisol did not change with statistical significance during either condition. A Friedman's ANOVA was used to evaluate within-subject differences in boys who participated in both the practice and match treatments $(N=17)$. Cortisol was the only hormone measure that, with statistical significance, increased more during the match than it did during practice. Analysis of the cortisol/DHEA ratios revealed a statistically significant decrease occurred during practice only. No statistical analysis was available for testosterone since all but seven samples were below the sensitivity of the assay $(<3.0 \mathrm{pg} / \mathrm{mL})$. These data suggest acute adrenal steroid hormone release in juvenile boys is sensitive to physical competition and responds differently than adult males.
\end{abstract}

Timothy S. McHale

mchalet2@unlv.nevada.edu

1 Department of Anthropology, University of Nevada, Las Vegas, 4505 S. Maryland Parkway, Box 455003, Las Vegas, NV 89154-5003, USA

2 ZRT Laboratory, Beaverton, OR 97008, USA

3 Department of Economics, University of California, Santa Barbara, CA 93106, USA 
Keywords Soccer - Exercise physiology $\cdot$ DHEA · Androstenedione $\cdot$ Cortisol $\cdot$ Juvenile

\section{Introduction}

Numerous studies have investigated steroid hormone responses to competition in human adults and adolescents (Edwards et al. 2006; Flinn et al. 2012; Gatti and De Palo 2011; Marceau et al. 2014; Salvador 2005; Trumble et al. 2012), with that work frequently relying upon athletic competition (e.g., individual or team sports participation) as a naturalistic competitive paradigm. Most of this research has focused on males and on the steroid hormones testosterone and cortisol. Furthermore, the endocrine balance between cortisol and Dehydroepiandrosterone (DHEA) has received attention as in indicator of hypothalamic-pituitary-adrenal axis activity (HPA activity). It was reported that cortisol/DHEA ratios exhibit stress reactive properties that are positively correlated during bouts of acute physical exercise and psychosocial stressors among adults and adolescents (Cadore et al. 2008; Izawa et al. 2008; Marceau et al. 2014). Here, we sought to extend this body of research by focusing on steroid hormone responses to athletic competition among juvenile boys.

While several studies have focused on adolescent male steroid hormone responses to athletic (e.g., intense physical activity among 10-year olds: Niemann et al. 2013) and psychosocial stressors (e.g., Hankin et al. 2010; public speaking in a psychology lab among 9-12-year olds: Yim et al. 2010), additional research has found evidence that adults, adolescents, and juveniles are capable of acute increase in DHEA during stressful situations (Izawa et al. 2008; Lennartsson et al. 2012; Shirtcliff et al. 2007). Furthermore, recent evidence has found acute bouts of physical exertion in adults promotes increases in testosterone, cortisol, DHEA and androstenedione concentrations (e.g., Cumming et al. 1986; Oliveira and Oliveira 2014; Trumble et al. 2013). These findings suggest adrenal hormone response may be sensitive to both psychosocial stressors and physical exertion, exhibiting both central (i.e., brain) and peripheral (i.e., enhanced muscle performance) effects. Given that the protracted period of juvenile development coincides with adrenarche, the pre-pubertal increase in adrenal androgen production, along with emergent sex-specific play patterned behaviors, one might anticipate a similar physiological response will be true among juvenile boys as they learn to navigate and prepare for the social challenges one would expect to face in adulthood (Benenson 2014; Campbell 2006; Del Giudice et al. 2009; Flinn and Ward 2004).

To our knowledge no studies have been published on juvenile boys' hormone responses to athletic competition. A growing understanding of adrenarche recognizes the increase in the weak androgens such as DHEA and androstenedione, released by the adrenal gland, with the potential to shape various features of human life history, including immune function and behavior (Campbell 2011; Del Giudice et al. 2009; Hochberg 2008). Several studies suggest relationships between baseline juvenile steroid hormone levels, such as DHEA, and behavioral and psychological measures of physical aggression (Azurmendi et al. 2006; Van Goozen et al. 1998). Whether adrenal steroid hormone responses to acute physical competition occur remains an open question, although some work (e.g., Flinn and England 1995) indicates boys in Dominica exhibit transient changes in cortisol in response to playing sports such as cricket. 
Here, we test three hypotheses: 1) DHEA, cortisol, androstenedione, and testosterone levels will increase in juvenile boys in response to physical competition; 2) the magnitude of hormone increase will be greater during a match than during practice, and 3 ) the cortisol/DHEA ratio will not significantly differ in either condition since we predict cortisol and DHEA will rise in conjunction with one another. The rationale for the second hypothesis is that a match may induce greater physical exertion, provide a more meaningful competitive environment, and activate more pronounced coalitionary psychological competition due to competing against out-group members versus one's in-group. For the purpose of this study, the soccer practice experimental condition, in which participants are engaged in a competitive contest against well-known peers/ teammates, was chosen to serve as the in-group competitive treatment. Similarly, the soccer match competition, which is characterized by a regularly scheduled soccer league match, in which one team competes against another unknown team of competitors, was selected as the out-group competitive treatment.

\section{Methods}

Participants were recruited from five all boys soccer teams that belonged to the Downtown Las Vegas Soccer Club organization, an elite soccer franchise: three U-10 teams consisting of 10 year old boys and two U-8 teams consisting of 8 year old boys. Parent Informed Consent Forms and Child Assent Forms were signed by all participants in the study. Each participant and parent was informed ahead of time to avoid consuming food one hour prior to the start of the soccer practice and one-hour before the warm-up period on the day of their soccer match, avoid drinking sugary drinks (e.g., Gatorade) and eating during the soccer practice and soccer match on the day of data collection, and informed not to run around until they provided a pre-practice and pre-match saliva sample. Three of the teams' data were collected between March and May of 2014 and two of the team's data were collected between the months of March and May of 2015. The study protocol was approved by the UNLV Institutional Review Board.

\section{Sample Collection, Assay, and Statistical Analysis}

Before and after soccer practice salivary samples were collected from juvenile boys who played on five different soccer teams. Four out of five teams had players provide salivary samples during a soccer match competition. Eighteen players from three U-10 teams and ten players from two U-8 teams provided salivary samples during a soccer practice. Thirteen total players from two U-10 teams and thirteen players from two U-8 teams provided salivary samples during a soccer match. Each team comprised of approximately ten total boys per team. Seven players from the U-10 Team 1, eight players from U-10 Team 2, three players from U-10 Team 3, five players from the U-8 Team 1, and five players from the U-8 Team $2(N=28)$ provided salivary samples during a soccer practice. Seven players from the U-10 Team 1, six players from the U10 Team 3, seven players from U-8 Team 1, and six players from the U-8 Team 2 provided salivary samples during the soccer match $(N=26)$. Due to unavoidable time of match conflicts (i.e., the team only had morning matches scheduled) the U-10 Team 2 
was not included in the match competition analysis. A total of seventeen participants provided saliva samples during both a soccer practice and soccer match competition and thus were available for within-subject comparison $(N=17)$. One of the benefits of within-subject comparison is that it provides a reduction in error variance associated with individual differences.

Both U-10 teams were victorious during their soccer matches, which resulted in 3-2 and 6-1 respective final scores. The U-8 Team 1 finished their match with a 1-1 tie while U-8 Team 2 lost $2-1$. Given the small sample size, and the fact that only one of the four teams lost during match play, we did not compare the possible moderating effects of winning and losing on adrenal hormone change in the current study.

To address circadian rhythms and nutrition-related factors (Groschl et al. 2003), efforts were made to standardize times of practices and games. For all five teams, before practice salivary measures were collected at approximately 5:20 pm and after practice salivary measures were collected at approximately 7:10 pm. On the day of the soccer match competition, all saliva collections were conducted prior to the warm-up period, approximately $30 \mathrm{~min}$ before the start of the match, between 4:30 pm and 6:45 pm, depending upon the start of the match for each of the four respective teams. The after match salivary samples were collected between 6:10 pm and 8:25 pm. Although some studies have reported anticipatory rise in steroid hormones occurring on the day of match competition prior to warm-ups, no appreciable increases were reported during the warm-up period in elite athletes (e.g., Edwards and Kurlander 2010). Thus, for purpose of the present study, each individual's before warm-up saliva samples represent beforematch competition values for that individual (Edwards and O'Neal 2009).

Subjects provided passive drool salivary samples $10 \mathrm{~min}$ before the start of their soccer practice and 10 min before the start of the warm-up period on the day of the soccer match. Post-practice and post-match salivary samples were collected $10 \mathrm{~min}$ after the completion of the soccer practice and $10 \mathrm{~min}$ after the conclusion of the match. The soccer practices all lasted 90 min with approximately 10-15 min spent on intermittent water breaks. Each practice consisted of boys participating in individual and team drills. The last 20-30 min of each practice was spent in an organized soccer scrimmage amongst teammates. Each player participant played equal amounts of time during the practice session. Each soccer match consisted of a 30 min warm-up period, two 25 min halves, and a 5 min halftime. Each team played with a full complement of eight soccer players to a side on the day of the soccer match competition and competed against an unknown team of boys. Each participant played relatively equal amounts of time on the soccer field (mean=39.8 $\mathrm{min} ; 30 \mathrm{~min}$ warm-up). Only one of the participants on the U-8 Team 2 played the first half as goalie (a position that requires a different physical exertion profile than the other positions, which all involve nearconstant running). For the entirety of the second half this player played on the field as defender. No other participants played goalie.

Salivary samples were assayed by ZRT Laboratory in Beaverton, Oregon using liquid chromatography-tandem mass spectrometry (LC-MS/MS), the most technically sophisticated and accurate method of analysis available. The intra-assay coefficient of variation for all four steroids range from 3.4 to $8.4 \%$ over the following hormone concentrations: testosterone $(9.8-83.5 \mathrm{pg} / \mathrm{mL})$; DHEA $(62.5-567 \mathrm{pg} / \mathrm{mL})$; androstenedione $(21.3-343 \mathrm{pg} / \mathrm{mL})$; cortisol $(0.4-5.6 \mathrm{ng} / \mathrm{mL})$. Inter-assay precision over the same hormone concentrations range from 4.1 to $15.2 \%$. 
Thirty-nine out of 106 total saliva samples $(36.8 \%)$ of DHEA were below the detection limit of the assay for DHEA $(<20 \mathrm{pg} / \mathrm{mL})$. Thirty out of 106 total saliva samples $(28.3 \%)$ of androstenedione $(<5.0 \mathrm{pg} / \mathrm{mL})$ were also below the detection limit. These low values are considered valuable data points representing low hormone concentrations even though exact measures are below sensitivity. Thus, each measure below sensitivity was assigned a value that is one half of the minimum detection limit: $10 \mathrm{pg} / \mathrm{mL}$ for DHEA and $2.5 \mathrm{pg} / \mathrm{mL}$ for androstenedione. No statistical analysis was available for testosterone since all but seven samples were below the sensitivity of the assay $(<3.0 \mathrm{pg} / \mathrm{mL})$.

A Shapiro-Wilk Test revealed DHEA, cortisol, androstenedione, and the percent in overall hormone change values for all three hormones were not normally distributed. Thus, we first conducted non-parametric analyses on the raw values were using a Wilcoxon Signed-Rank Sum Test and Friedman's ANOVA. In addition, we applied log base-2 transformations to normalize the distributions for DHEA, cortisol, androstenedione, and to the molar cortisol/DHEA ratio data. We then performed a standard linear regression analysis on the transformed data, to test all three hypotheses. Note that although the transformed data appear normally distributed, under the Gauss-Markov Theorem, disturbance terms need not be normally distributed to conduct valid linear regression analysis (Casella and Berger 2002; Golberg and Cho 2004). Log base-2 was chosen because of the straightforward interpretation: a value of 1.0 when comparing post- and pre-match hormone levels implies a doubling in measurement; a value of 2.0 implies a quadrupling; a value of -1.0 implies a halving, and a value of -2.0 implies the post-match value is only one-fourth the pre-match value.

\section{Results}

The participants' general baseline characteristics and hormone concentration values are shown in Table 1, before log transformation was conducted. As expected in our primary hypothesis, several steroid hormones were significantly elevated during soccer practice and match competition. A Wilcoxon Signed-Rank Sum Test revealed the median concentration of DHEA after the soccer practice $(M d n=28.04 \mathrm{pg} / \mathrm{mL})$ was statistically significantly higher compared to the before practice DHEA levels $(M d n=22.89 \mathrm{pg} / \mathrm{mL})$, $Z=-2.81, p=0.005, \mathrm{r}=-0.53$. DHEA was also significantly higher after the match $(M d n=22.65 \mathrm{pg} / \mathrm{mL})$ compared to before match levels $(M d n=10.00 \mathrm{pg} / \mathrm{mL})$, $Z=-2.24, p=0.025, \mathrm{r}=-0.44$. This trend was further supported by the fact that androstenedione median levels were significantly higher post-match $(M d n=$ $9.30 \mathrm{pg} / \mathrm{mL})$ compared to pre-match levels $(M d n=7.31 \mathrm{pg} / \mathrm{mL}), Z=-3.25, p=$ $0.001, \mathrm{r}=-0.64$. Participation in a soccer practice did not elicit a statistically significantly difference in androstenedione after practice $(M d n=7.96 \mathrm{pg} / \mathrm{mL})$ compared to before practice levels $(M d n=7.05 \mathrm{pg} / \mathrm{mL}), Z=-1.14, p=0.253, \mathrm{r}=-0.22$. Before $(M d n=0.48 \mathrm{ng} / \mathrm{mL})$ and after $(M d n=0.38 \mathrm{ng} / \mathrm{mL})$ soccer practice levels and before $(M d n=0.53 \mathrm{ng} / \mathrm{mL})$ and after $(M d n=0.60 \mathrm{ng} / \mathrm{mL})$ soccer match levels of cortisol did not statistically significantly differ during the practice $(Z=-1.50, p=0.133$, $\mathrm{r}=-0.28)$ or match $(Z=-1.16, p=0.248, \mathrm{r}=-0.23)$ treatments.

DHEA levels increased in the majority of subjects, both post-match and postpractice: 14 of 26 boys involved in a match saw DHEA increases, while 4 saw 
Table 1 Descriptive statistics for mean juvenile boys' salivary hormone measures collected before and after a soccer practice $(N=28)$ and before and after a soccer match $(N=26)$, including age, BMI, and mean percent change in DHEA, cortisol, and androstenedione post-practice and post-match competition

\begin{tabular}{|c|c|c|c|c|}
\hline & Mean & SD & Min & Max \\
\hline Age (months) & 113.97 & 12.30 & 95.00 & 129.00 \\
\hline BMI $(\mathrm{kg} \cdot \mathrm{m}-2)$ & 17.77 & 2.12 & 14.41 & 24.11 \\
\hline DHEA 10 mins before practice $(\mathrm{pg} / \mathrm{mL})$ & 27.63 & 23.19 & 10.00 & 95.72 \\
\hline DHEA 10 mins after practice $(\mathrm{pg} / \mathrm{mL})$ & $60.30 *$ & 112.57 & 10.00 & 543.24 \\
\hline$\%$ change in DHEA 10 mins after practice & $77.9 \%$ & $155.9 \%$ & $-72.0 \%$ & $618.7 \%$ \\
\hline DHEA 10 mins before match $(\mathrm{pg} / \mathrm{mL})$ & 22.37 & 18.85 & 10.00 & 84.19 \\
\hline DHEA 10 mins after match $(\mathrm{pg} / \mathrm{mL})$ & $39.57 *$ & 41.98 & 10.00 & 157.65 \\
\hline$\%$ change in DHEA 10 mins after match & $113.5 \%$ & $232.4 \%$ & $-73.8 \%$ & $1091.4 \%$ \\
\hline Cortisol 10 mins before practice $(\mathrm{ng} / \mathrm{mL})$ & 0.56 & 0.31 & 0.18 & 1.44 \\
\hline Cortisol 10 mins after practice $(\mathrm{ng} / \mathrm{mL})$ & 0.81 & 1.83 & 0.11 & 9.98 \\
\hline$\%$ change in cortisol 10 mins after practice & $73.0 \%$ & $382.6 \%$ & $-79.3 \%$ & $1936.7 \%$ \\
\hline Cortisol 10 mins before match $(\mathrm{ng} / \mathrm{mL})$ & 0.70 & 0.59 & 0.18 & 2.93 \\
\hline Cortisol 10 mins after match $(\mathrm{ng} / \mathrm{mL})$ & 0.94 & 0.86 & 0.17 & 3.20 \\
\hline$\%$ change in cortisol 10 mins after match & $80.9 \%$ & $184.7 \%$ & $-76.7 \%$ & $683.3 \%$ \\
\hline Cortisol/DHEA molar ratio before practice & 24.05 & 17.32 & 2.08 & 89.91 \\
\hline Cortisol/DHEA molar ratio after practice & $27.23^{*}$ & 62.51 & 0.50 & 338.25 \\
\hline Cortisol/DHEA molar ratio before game & 41.25 & 49.48 & 3.52 & 232.85 \\
\hline Cortisol/DHEA molar ratio after game & 35.60 & 51.42 & 3.41 & 254.47 \\
\hline Androstenedione 10 mins before practice $(\mathrm{pg} / \mathrm{mL})$ & 7.27 & 4.93 & 2.50 & 24.09 \\
\hline Androstenedione 10 mins after practice $(\mathrm{pg} / \mathrm{mL})$ & 8.67 & 5.35 & 2.50 & 26.05 \\
\hline$\%$ change in androstenedione 10 mins after practice & $58.7 \%$ & $129.6 \%$ & $-64.1 \%$ & $510.4 \%$ \\
\hline Androstenedione 10 mins before match $(\mathrm{pg} / \mathrm{mL})$ & 7.08 & 4.58 & 2.50 & 18.11 \\
\hline Androstenedione 10 mins after match $(\mathrm{pg} / \mathrm{mL})$ & $10.63 *$ & 7.17 & 2.50 & 25.46 \\
\hline$\%$ change in androstenedione 10 mins after match & $63.4 \%$ & $101.2 \%$ & $-57.6 \%$ & $342.9 \%$ \\
\hline
\end{tabular}

Note: Values are presented before log transformation

* significant at confidence level greater than $95 \%$

decreases and 8 saw no change. Similarly, 17 of 28 boys involved in a practice saw DHEA increases, while 5 saw decreases and 6 saw no change. Subjects' log-base 2 DHEA levels increased an average of 0.578 post-match $(p=0.021)$, corresponding to a $49 \%$ characteristic increase in DHEA saliva concentration, and by an average of 0.479 post-practice $(p=0.022)$, corresponding to a $39 \%$ characteristic increase.

Similarly, 18 of 26 subjects experienced increases in androstenedione levels after a match, while 3 experienced decreases and 5 saw no change; 14 of 28 subjects saw an increase in androstenedione levels after a practice, with 10 seeing decreases and 4 seeing no change. These subjects exhibited a characteristic increase of $45 \%$ in androstenedione levels post-match $(p=0.002)$, but the post-practice increase of $23 \%$ was not statistically significant $(p=0.136)$.

Of the 26 subjects who participated in a soccer match competition, 16 experienced increases in cortisol levels, while 10 experienced decreases. Interestingly, fully 20 of 
the 28 subjects who participated in a soccer practice exhibited decreases in measured cortisol levels, with just 7 experiencing increases and 1 who experienced no change. However, due to the small sample size these changes in cortisol levels were not statistically significant for either the post-match or post-practice treatments, with pvalues of 0.340 and 0.395 , respectively.

We also tested our hypothesis that the cortisol/DHEA ratio would remain the same after both the soccer match and practice treatments. Post-match, we found that 12 of 26 boys' cortisol/DHEA ratio increased, while the remaining 14 saw a decrease in this ratio. By contrast, however, 22 of 28 boys who participated in practice saw a decrease in their cortisol/DHEA ratio, while just 6 experienced an increase in this ratio. While the characteristic post-match drop of $20 \%$ was not statistically significant, likely due to small sample size and resulting larger standard errors, the characteristic cortisol/DHEA ratio dropped by a statistically significant $39 \%(p=0.015)$ post-practice. The above findings are summarized in Table 2.

To test our hypothesis of differentially higher hormone responses resulting from match vis-à-vis practice play, we conducted a series of Friedman's ANOVA analyses. We thereby evaluated the within-subject differences in medians between the soccer practice treatment for DHEA $(M d n=29.71 \mathrm{pg} / \mathrm{mL})$, androstenedione $(M d n=2.95 \mathrm{pg} / \mathrm{mL})$, and cortisol $(M d n=-29.5 \mathrm{ng} / \mathrm{mL})$, and the soccer match treatment for DHEA $(M d n=30.28 \mathrm{pg} / \mathrm{mL})$, androstenedione $(M d n=9.51 \mathrm{pg} / \mathrm{mL})$,

Table 2 Summary of linear regression results, conducted on DHEA, cortisol, androstenedione levels and on molar cortisol/DHEA ratios, for data collected before and after a soccer practice $(N=28)$ and before and after a soccer match $(N=26)$

DHEA Cortisol Androstenedione Cortisol/DHEA ratio

\begin{tabular}{|c|c|c|c|c|}
\hline \multicolumn{5}{|l|}{ Post-Match Treatment } \\
\hline Number with post-match increase & 14 & 16 & 8 & 12 \\
\hline Number with no post-match change & 8 & 0 & 5 & 0 \\
\hline Number with post-match decrease & 4 & 10 & 3 & 14 \\
\hline Total participating in match & 26 & 26 & 26 & 26 \\
\hline Average log-base 2 hormone level change & $0.578^{*}$ & 0.256 & $0.536^{* *}$ & -0.323 \\
\hline $\begin{array}{l}\text { Characteristic change } \\
\left(2^{\wedge} \text { avb log-base } 2 \text { change }\right)\end{array}$ & $49 \%$ & $19 \%$ & $45 \%$ & $-20 \%$ \\
\hline$p$-value & 0.021 & 0.340 & 0.002 & 0.274 \\
\hline \multicolumn{5}{|l|}{ Post-Practice Treatment } \\
\hline Number with post-practice increase & 17 & 7 & 14 & 6 \\
\hline Number with no post-practice change & 6 & 1 & 4 & 0 \\
\hline Number with post-practice decrease & 5 & 20 & 10 & 22 \\
\hline Total participating in practice & 28 & 28 & 28 & 28 \\
\hline Average log-base 2 hormone level change & $0.479 *$ & -0.223 & 0.299 & $-0.702 *$ \\
\hline $\begin{array}{l}\text { Characteristic change } \\
\left(2^{\wedge} \text { avb log-base } 2 \text { change }\right)\end{array}$ & $39 \%$ & $-14 \%$ & $23 \%$ & $-39 \%$ \\
\hline$p$-value & 0.022 & 0.395 & 0.136 & 0.015 \\
\hline
\end{tabular}

* significant at confidence level greater than $95 \%$;* significant at confidence level greater than $99 \%$ 
and cortisol $(M d n=12.86 \mathrm{ng} / \mathrm{mL})$, with statistical analyses relying upon the use of percent of overall hormone change that occurred for those players who participated in both treatments. A statistically significant difference was found for cortisol, $\chi^{2}(1)=4.77$, $p=0.029$, with a Kendall's coefficient of concordance of 0.28 indicating a fairly strong difference between the soccer practice and soccer match treatments, such that cortisol levels decreased during the soccer practice but increased during the soccer match. No significant difference in hormone change occurred between the soccer match and soccer practice treatments for DHEA, $\chi^{2}(1)=0.67, p=0.796$, or androstenedione, $\chi^{2}(1)=2.25$, $p=0.134$.

\section{Discussion}

The results partially support our primary hypothesis: boys exhibited statistically significant increases in DHEA, but not cortisol or testosterone, in response to both a soccer practice and soccer match competition. Androstenedione exhibited a significant increase during match play only. Cortisol, a well-known biomarker for psychosocial stress, exhibited a statistically significant difference between the soccer practice and soccer match treatments, such that players who participated in both conditions exhibited a significant post-practice decrease when compared to the post-match increase.

However, in contrast to our secondary hypothesis, no between group differences were observed for DHEA, androstenedione or testosterone. Lastly, the relationship between cortisol/DHEA ratios demonstrated a significant decrease during the soccer practice condition, while no statistically significant change was observed during the soccer match. Several researchers have speculated upon the complex relationship between DHEA, an ACTH-regulated steroid that possesses anti-glucocorticoid properties, and cortisol (e.g., Flinn et al. 2011). Particularly, that DHEA and cortisol might be antagonistic in binding the glucocorticoid receptor. We propose that a decrease in cortisol/DHEA ratios likely occurred in the practice condition because DHEA continued to significantly increase during both practice and match treatments, while cortisol begins to drop for many of the players during the soccer practice.

This result is of interest because it suggests DHEA synthesis may be capable of independently elevating during physical competition, even as cortisol stays level or declines. It also hints at the possibility of a different kind of role for DHEA and cortisol: DHEA functioning as a hormonal response to physical competition, or physical activity in general, would be consistent with a finding of significant increases in DHEA concentrations both when competing against out-group members, and when competing only with in-group members. By contrast, cortisol serving as a trigger for (or a result of) a coalitional psychology response, would be consistent with cortisol levels increasing during match play but not during practice play. Both these phenomena taken together would be consistent with cortisol/DHEA ratios that fall during practice play, but fall less or stay stable during match play.

In light of these findings we speculate that steroid hormone regulatory pathways, which are well-known to be activated in response to physical and psychosocial competitive stimuli in adult males and across many vertebrates (e.g., acute rise in testosterone during territorial defense in avian species), may vary across life history stages in humans and exhibit pleiotropic effects (Flinn et al. 2011), particularly during 
the juvenile stage of development. Preliminary support for this hypothesis has been found in monogamous seasonally breeding male song sparrows (Melospiza melodia), in which neuroendocrine shifts in baseline steroid hormones levels and acute reactive effects have been observed to fluctuate annually across the breeding and non-breeding seasons (Pradhan et al. 2010; Soma et al. 2008; Wingfield et al. 1990). Investigations of avian species that exhibit year-round territorial aggression have demonstrated nonbreeding aggression can be independent from circulating testosterone levels when gonadal androgen synthesis and plasma androgen levels are low (Soma 2006; Soma et al. 2008; Pradhan et al. 2010; Wingfield and Soma 2002). Recent evidence has shown that when male song sparrows are presented with a simulated territorial intrusion during the non-breeding season an acute increase in the enzyme $3 \beta$-hydroxysteroid dehydrogenase $/ \Delta 5-\Delta 4$ isomerase (3ß-HSD) is observed in the areas of the telencephalon associated with regulating aggression in birds, a brain region that is homologous to the medial amygdala in humans. The enzyme $3 \beta-\mathrm{HSD}$ is responsible for converting DHEA to the more active androgen androstenedione (Schlinger et al. 2008). Taken together, these data provide support that non-breeding song sparrows exhibit an increase in local androgen synthesis and a shift in the neuroendocrine mechanisms responsible for regulating aggression and that most likely reflects adaptive life history tradeoffs (Pradhan et al. 2010). By adjusting baseline and acute steroid hormone production in response to seasonal reproductive changes male song sparrows demonstrate behavioral flexibility while avoiding the fitness costs associated with immunosuppressive effects (i.e., down regulation) and metabolic costs of maintaining chronically high levels of testosterone (Hau 2007; Muehlenbein and Bribiescas 2005; Schroderus et al. 2010). Despite birds and humans representing a distant phylogenetic relationship, it is conceivable that similar energy efficient neuroendocrine mechanisms evolved as a consequence of life history tradeoffs in juvenile boys as well, in order to facilitate an appropriate behavioral response to male-male competition and social challenges, at a low-cost, and at a time in the life course when reproduction is of no consequence. Given that saliva hormone measures in boys represent peripheral synthesis, with the assumption some of these hormones may cross the blood-brain barrier and reflect local synthesis, it raises the intriguing question as to the potential functional role acute increases in DHEA and androstenedione may serve boys during bouts of physical competition. Perhaps the finding of an acute rise in androstenedione during the soccer match competition represents a heightened sensitivity to the social competitive milieu, or potentially it reflects an anabolic effect of increased muscle performance due to the demand for increased physical exertion. These speculations indicate that future studies are warranted to investigate the independent variables that are responsible for stimulating acute steroid hormone release in boys.

The preliminary findings presented here suggest juvenile boys' cortisol responsiveness may reflect boys' differential sensitivity to various competitive challenges and type of competitors. However, given the potential confounded effects related to differences in duration of physical play between the soccer practice and soccer match, and limitations of this study noted below, it is unclear the extent to which we can infer inter- and intragroup psychosocial competition effects. The lack of measurable testosterone concentrations in almost all samples is consistent with an expectation of low male juvenile testosterone levels in adrenarche, but also shows that the 8 to 10 -year old boys' hormone responses to soccer competition do not mirror those of adults, for whom testosterone 
responses to physical and psychosocial competition, including more pronounced outgroup effects, have often been found (Flinn et al. 2012; Oxford et al. 2010).

There are several key contributions made by this study. This study shows that juvenile hormone concentrations, particularly DHEA and androstenedione, are responsive to athletically-based competition. More specifically, these data confirm adrenal steroid hormone release is sensitive to physical competition and capable of rapid changes in juvenile boys. Such data may be of empirical interest to scholars of exercise physiology, behavioral endocrinology, and human life history, in part because they broaden the discussion beyond the typical adult-age range of participants. The findings also raise questions as to whether such changes might be more pronounced in boys than girls, and whether such changes shape life history trajectories (e.g., reward in response to competitive success), such as the potential for feedback effects of steroid hormone change on subsequent patterns of behavior, as found for other work on adult testosterone (e.g., Mehta and Josephs 2006). In a related vein, the null findings concerning boys' testosterone responses to soccer competition, tracing to the low concentrations of boys' testosterone in this age range, also argues against any straightforward or simple extrapolations of the so-called "Challenge Hypothesis" (Wingfield et al. 1990) to juvenile boys. This is important because a large body of research on humans and other animals addresses male testosterone increases to competition in reproductive contexts, as conceptualized by the “Challenge Hypothesis" (see Archer 2006; Carré and Olmstead 2015).

Another strength of the study is that it entailed simultaneously measuring four different steroid hormones in juvenile boys, and during two competitive team conditions; most research on salivary hormones and competition measures one or two (e.g., testosterone and cortisol) hormones, and is focused primarily on adults. In addition, the steroid hormone concentrations were determined using LC-MS/MS, which has been shown to exhibit better sensitivity and accuracy than other common testing methods, such as enzyme immunoassay or radioimmunoassay (e.g., Wang et al. 2004). LC-MS/ MS avoids any possibility of cross reactivity and is considered the optimal method for conducting salivary steroid hormone research.

The strengths of the study should also be considered in light of several limitations. The small sample size limits the extent to which we can interpret the findings. Additionally, the duration of time spent playing in the soccer practice and soccer match competitions differ. Therefore, it remains to be seen the extent to which salivary steroid hormone change emerges as a result of participant's perceived assessment of inter- and intra-group coalitional competition, amount of physical exertion, or a combination of both physical and psychosocial effects. Future studies attempting to assess juveniles' hormone responses to inter- and intra-group competitive contexts should ensure participants spend equal amounts of time engaged in physical competition during an intrasquad scrimmage that mirrors match competition conditions. Participants did not provide information regarding any known steroid medications they were currently prescribed or currently taking prior to participating in the study. To our knowledge all participants were healthy boys with no known outstanding medical issues, however, not having participants fully disclose their medical history potentially introduces another confound that needs to be controlled for in future studies. Future research in this arena will likely be fruitful, benefitting by incorporating larger sample sizes, measures of physical exertion (e.g., heart monitors), indicators of pubertal maturation, such as providing a clinician's assessment of Tanner Stages (Tanner 1962) or requiring 
participants answer the self-reported Pubertal Development Scale (Petersen et al. 1988), and additional psychosocial competitive paradigms in a broader array of cross-cultural contexts to provide a more nuanced understanding of the association between physical exertion, psychosocial challenges, and acute steroid hormone response in boys. Such work will help reveal how developing young males prepare and respond to a competitive world, as the endocrine glands attest, even before having reached adulthood.

Acknowledgments We would like to sincerely thank the Downtown Las Vegas Soccer Club, coaches, parents, and players for their enthusiastic participation during this study. In addition, we would like to give special thanks to David Kimball at ZRT Laboratory for running the hormone assays by LC-MS/MS and to the rest of the ZRT staff who contributed on this project.

\section{References}

Archer, J. (2006). Testosterone and human aggression: an evaluation of the "challenge hypothesis.". Neuroscience and Biobehavioral Reviews, 30(3), 319-345.

Azurmendi, A., Braza, F., Garcia, A., Braza, P., Munoz, J., \& Sanchez-Martin, J. (2006). Aggression, dominance and affiliation: their relationships with androgen levels and intelligence in 5-year-old children. Hormones and Behavior, 50, 132-140.

Benenson, J. F. (2014). Warriors and Worriers: The Survival of the Sexes. Oxford University Press.

Cadore, E., Lhullier, F., Brentano, M., Silva, E., Ambrosini, M., Spinelli, R., \& Kruel, L. (2008). Correlations between serum and salivary hormonal concentrations in response to resistance exercise. Journal of Sports Sciences, 26(10), 1067-1072.

Campbell, B. (2006). Adrenarche and the evolution of human life history. American Journal of Human Biology, 18, 569-589.

Campbell, B. (2011). Adrenarche in comparative perspective. American Journal of Human Biology, 23, 44-52.

Carré, J. M., \& Olmstead, N. A. (2015). Social neuroendocrinology of human aggression: examining the role of competition-induced testosterone dynamics. Neuroscience, 286, 171-186.

Casella, G., \& Berger, R. L. (2002). Statistical Inference (2nd ed.). Pacific Grove: Thomas.

Cumming, D. C., Brunsting, L. A., Strich, G., Ries, A. L., \& Rebar, R. W. (1986). Reproductive hormone increases in response to acute exercise in men. Medicine and Science in Sports and Exercise, 18(4), 369373.

Del Giudice, M., Angeleri, R., \& Manera, V. (2009). The juvenile transition: a developmental switch point in human life history. Developmental Review, 29(1), 1-31.

Edwards, D. A., \& Kurlander, L. S. (2010). Women's intercollegiate volleyball and tennis: effects of warm-up, competition, and practice on saliva levels of cortisol and testosterone. Hormones and Behavior, $58,606-613$.

Edwards, D. A., \& O’Neal, J. L. (2009). Oral contraceptives decrease saliva testosterone but do not affect the rise in testosterone associated with athletic competition. Hormones and Behavior, 56(2), 195-198.

Edwards, D. A., Wetzel, K., \& Wyner, D. R. (2006). Intercollegiate soccer: saliva cortisol and testosterone are elevated during competition, and testosterone is related to status and social connectedness with teammates. Physiology and Behavior, 87, 135-143.

Flinn, M. V., \& England, B. (1995). Childhood stress and the family environment. Current Anthropology, 36, $854-866$.

Flinn, M. V., \& Ward, C. V. (2004). Evolution of the social child. In B. Ellis \& D. Bjorklund (Eds.), Origins of the social mind: evolutionary psychology and child development. London: Guilford Press.

Flinn, M. V., Nepomnaschy, P. A., Muehlenbein, M. P., \& Ponzi, D. (2011). Evolutionary functions of early social modulation of hypothalamic-pituitary-adrenal axis development in humans. Neuroscience \& Biobehavioral Reviews, 35(7), 1611-1629.

Flinn, M. V., Ponzi, D., \& Muehlenbein, M. P. (2012). Hormonal mechanisms for regulation of aggression in human coalitions. Human Nature, 23, 68-88. 
Gatti, R., \& De Palo, E. F. (2011). An update: salivary hormones and physical exercise. Scandinavian Journal of Medicine \& Science in Sports, 21(2), 157-169.

Golberg, M. A., \& Cho, H. A. (2004). Introduction to Regression Analysis. Ashurst: Wessex Institute of Technology.

Groschl, M., Rauh, M., \& Dorr, H. G. (2003). Circadian rhythm of salivary cortisol, 17 alpha- hydroxyprogesterone, and progesterone in healthy children. Clinical Chemistry, 49, 1688-1691.

Hankin, B. L., Badanes, L. S., Abela, J. R., \& Watamura, S. E. (2010). Hypothalamic-pituitary-adrenal axis dysregulation in dysphoric children and adolescents: Cortisol reactivity to psychosocial stress from preschool through middle adolescence. Biological Psychiatry, 68(5), 484-490.

Hau, M. (2007). Regulation of male traits by testosterone: implications for the evolution of vertebrate life histories. BioEssays, 29(2), 133-144.

Hochberg, Z. E. (2008). Juvenility in the context of life history theory. Archives of Disease in Childhood, 93(6), 534-539.

Izawa, S., Sugaya, N., Shirotsuki, K., Yamada, K. C., Ogawa, N., Ouchi, Y., Nagano, Y., Suzuki, K., \& Nomura, S. (2008). Salivary dehydroepiandrosterone secretion in response to acute psychosocial stress and its correlations with biological and psychological changes. Biological Psychology, 79(3), 294-298.

Lennartsson, A. K., Kushnir, M. M., Bergquist, J., \& Jonsdottir, I. H. (2012). DHEA and DHEA- S response to acute psychosocial stress in healthy men and women. Biological Psychology, 90(2), 143-149.

Marceau, K., Shirtcliff, E. A., Hastings, P. D., Klimes-Dougan, B., Zahn-Waxler, C., Dorn, L. D., \& Susman, E. J. (2014). Within-adolescent coupled changes in cortisol with DHEA and testosterone in response to three stressors during adolescence. Psychoneuroendocrinology, 41, 33-45.

Mehta, P. H., \& Josephs, R. A. (2006). Testosterone change after losing predicts the decision to compete again. Hormones \& Behavior, 50(5), 684-692.

Muehlenbein, M. P., \& Bribiescas, R. G. (2005). Testosterone-mediated immune functions and male life histories. American Journal of Human Biology, 17(5), 527-558.

Niemann, C., Wegner, M., Voelcker-Rehage, C., Holzweg, M., Arafat, A. M., \& Budde, H. (2013). Influence of acute and chronic physical activity on cognitive performance and saliva testosterone in preadolescent school children. Mental Health and Physical Activity, 6, 197-204.

Oliveira, G. A., \& Oliveira, R. F. (2014). Androgen responsiveness to competition in humans: the role of cognitive variables. Neuroscience and Neuroeconomics, 3, 19-32.

Oxford, J., Ponzi, D., \& Geary, D. C. (2010). Hormonal responses differ when playing violent video games against an ingroup and outgroup. Evolution and Human Behavior, 31(3), 201-209.

Petersen, A. C., Crockett, L. J., Richards, M., \& Boxer, A. (1988). A self-report measure of pubertal status: reliability, validity, and initial norms. Journal of Youth and Adolescence, 17, 117-133.

Pradhan, D. S., Newman, A. E., Wacker, D. W., Wingfield, J. C., Schlinger, B. A., \& Soma, K. K. (2010). Aggressive interactions rapidly increase androgen synthesis in the brain during the non-breeding season. Hormones and Behavior, 57(4), 381-389.

Salvador, A. (2005). Coping with competitive situations in humans. Neuroscience and Biobehavioral Reviews, 29(1), 195-205.

Schlinger, B. A., Pradhan, D. S., \& Soma, K. K. (2008). 3 $\beta$-HSD activates DHEA in the songbird brain. Neurochemistry International, 52(4), 611-620.

Schroderus, E., Jokinen, I., Koivula, M., Koskela, E., Mappes, T., Mills, S. C., Oksanen, T. A., \& Poikonen, T. (2010). Intra- and intersexual trade-offs between testosterone and immune system: implications for sexual and sexually antagonistic selection. American Naturalist, 176(4), E90-E97.

Shirtcliff, E., Zahn-Waxler, C., Klimes-Dougan, B., \& Slattery, M. (2007). Salivary dehydroepiandrosterone responsiveness to social challenge in adolescents with internalizing problems. Journal of Child Psychology and Psychiatry, 48(6), 580-591.

Soma, K. K. (2006). Testosterone and aggression: berthold, birds and beyond. Journal of Neuroendocrinology, $18(7), 543-551$.

Soma, K. K., Scotti, M. A. L., Newman, A. E., Charlier, T. D., \& Demas, G. E. (2008). Novel mechanisms for neuroendocrine regulation of aggression. Frontiers in Neuroendocrinology, 29(4), 476-489.

Tanner, J. M. (1962). Growth and adolescence. Springfield: Thomas.

Trumble, B. C., Cummings, D., von Rueden, C., O’Connor, K. A., Smith, E. A., Gurven, M., \& Kaplan, H. (2012). Physical competition increases testosterone among Amazonian forager-horticulturalists: a test of the 'challenge hypothesis'. Proceedings of the Royal Society B: Biological Sciences, 279, 2907-2912.

Trumble, B. C., Cummings, D. K., O’Connor, K. A., Holman, D. J., Smith, E. A., Kaplan, H. S., \& Gurven, M. D. (2013). Age-independent increases in male salivary testosterone during horticultural activity among Tsimane forager-farmers. Evolution and Human Behavior, 34(5), 350-357. 
Van Goozen, S. H., Matthys, W., Cohen-Kettenis, P. T., Thijssen, J. H., \& van Engeland, H. (1998). Adrenal androgens and aggression in conduct disorder prepubertal boys and normal controls. Biological Psychiatry, 43(2), 156-158.

Wang, C., Catlin, D. H., Demers, L. M., Starcevic, B., \& Swerdloff, R. S. (2004). Measurement of total serum testosterone in adult men: comparison of current laboratory methods versus liquid chromatographytandem mass spectrometry. Journal of Clinical Endocrinology and Metabolism, 89, 534-543.

Wingfield, J. C., \& Soma, K. K. (2002). Spring and autumn territoriality in song sparrows: same behavior, different mechanisms? Integrative and Comparative Biology, 42(1), 11-20.

Wingfield, J. C., Hegner, R. E., Dufty, A. M., Jr., \& Ball, G. F. (1990). The "challenge hypothesis": theoretical implications for patterns of testosterone secretion, mating systems, and breeding strategies. American Naturalist, 136(6), 829-846.

Yim, I. S., Quas, J. A., Cahill, L., \& Hayakawa, C. M. (2010). Children's and adults' salivary cortisol responses to an identical psychosocial laboratory stressor. Psychoneuroendocrinology, 35, 241-248. 